Market Frictions, Technology Adoption ANd Economic Growth

by

Been-Lon Chen, Jie-Ping Mo, and Ping Wang

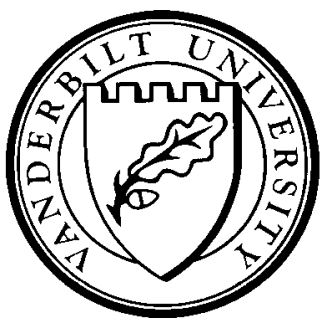

Working Paper No. 00-W34

August 1999

Revised August 2000

DEPARTMENT OF ECONOMICS

VANDERBILT UNIVERSITY

NASHVILLE, TN 37235

www.vanderbilt.edu/econ 


\title{
Market Frictions, Technology Adoption and Economic Growth
}

\author{
Been-Lon Chen \\ Institute of Economics \\ Academia Sinica, Taiwan \\ Jie-Ping Mo \\ Institute of Economics \\ Academia Sinica, Taiwan \\ Ping Wang \\ Department of Economics \\ Vanderbilt University, USA
}

First Draft: August 1999

This Version: August 2000

\begin{abstract}
$\underline{\text { Abstract }}$
This paper develops an endogenous growth model with labor market matching and technology adoption. While labor market search and entry frictions lengthen technology diffusion, exogenous technology arrival may creatively destruct jobs in the short run. Such interrelationships give rise to multiple equilibria (global and local indeterminacy) under which a small autonomous technological improvement may create a large growth effect. We characterize the effects of exogenous technology arrival on equilibrium matching, adoption effort, wage and the overall dispersion of wages. Social inefficiency arises as a result of individuals' failure to account for free-rider, thick-matching, job-destruction effects in making technology adoption decision.
\end{abstract}

Keywords: Technological Diffusion, Labor Market Search and Matching, Endogenous Growth.

JEL Classification: D83, O33, O41.

Acknowledgment: We have benefitted from comments and suggestions from Boyan Jovanovic, Derek Laing, Steve Turnovsky, Henry Wan and two anonymous referees. Any remaining errors are, needless to say, our own responsibility.

Address for Correspondence: Ping Wang, Department of Economics, Vanderbilt University, Nashville, TN 37235; 615-322-2388 (phone); 615-343-8495 (fax); ping.wang@ vanderbilt.edu (E-mail). 


\section{Introduction}

Technological advancement is widely believed as one of the most importance driving forces for longrun economic development. While the majority of the existing literature is devoted to modeling investment in R\&D, the causes and consequences of technology adoption have not been thoroughly studied. More specifically, while it is observed that new technology is adopted gradually, there is absent of a complete knowledge in understanding the dynamic process through which market frictions influence the technology adoption decision. While it is recognized that technology adoption can destruct jobs, there is lack of a systematic assessment on the welfare implications of adoption activity in the presence of search and entry barriers. These open issues are important not only because they are essential for the interplays between technical progress and economic growth, but also because they are crucial for development planners to design effective tax incentives as well as employment and industrial policies. The present paper provides a first step toward addressing these issues within a dynamic general-equilibrium framework.

Previous studies of technology adoption can be divided into three branches. Rustichini and Schmitz (1990) model the adoption activity based on the process of imitation. Parente (1995) and Parente and Prescott $(1994,1999)$ consider adoption barriers and their implications for economic growth. Chen and Shimomura (1998) treat adoption as a risky investment and examine its consequence for industrialization. However, except for Parente and Prescott (1999), adoption barriers have been either ignored or taken as exogenous to the economic system. While Parente and Prescott (1999) illustrate the presence of barriers as a consequence of the monopoly rent seeking behavior of the incumbents, the deep-structure primitives underlying the adoption barriers have not been fully explored.

It is natural to consider a search-theoretic approach that highlights particularly the underlying adoption barriers. We focus on two types of imperfections: (i) search frictions, representing the costly delay of job matches, and (ii) entry frictions, representing the costly start-up of a vacancy. We generalize the matching and bargaining frameworks promulgated in the seminal works of Diamond (1982) and Pissarides 
(1985) to allow workers and machines to locate each other in the labor market in which both workers' and machines' contact rates and the masses of search workers and unmatched machines are endogenously determined in the system. Technology knowledge grows endogenously, depending on the society's average technology adoption effort following the Romer (1990) convention in forms of uncompensated spillovers. Adoption decision is made to achieve maximum net expected value and the equilibrium adoption frequency therefore determines the rate at which new technology diffuses. By stripping down to a bare-bone structure while maintaining the main features of the model, the dynamics of the system reduces to two dimensional, in terms of the population of search workers and the surplus accrued from a successful match. This enables an analytic characterization of the dynamic properties of the model.

The main findings of our paper are delineated as follows. First, labor market search and entry frictions tend to discourage adoption effort and lengthen technology diffusion. Second, with exogenous job destruction, an increase in the rate of exogenous technology arrival or average growth spurs the worker's contact rate, encourages adoption activity and raises the wages, yet its influence on the overall wage dispersion is ambiguous due to the opposing effects via changes in the population of the long-term unemployed and the newly employed. Third, dynamic interactions between endogenous matching and endogenous technology adoption give rise to both global and local indeterminacy. In the case with multiple balanced growth paths, a small autonomous technological improvement may create a large growth effect, enabling an economy to leapfrog from a low-growth trap to a high-growth equilibrium. Fourth, with endogenous job destruction, an increase in the rate of exogenous technology arrival may lead to creative destruction of jobs. Such destruction is more severe in the short run and in an economy with effective job matching. Finally, the decentralized solution is socially inefficient: individuals may under- or over-invest in technology adoption, as they fail to account for free-rider, thick-matching and endogenous job destruction effects.

Our paper contributes to the conventional wisdom in at least four aspects. First, the effect of trade 
barriers on technology adoption in our model works through endogenous search and entry frictions which is different than the predominant frameworks in the field by and Parente (1995) and Parente and Prescott (1994, 1999). Second, in contrast with previous work on endogenous growth, both global and local multiple equilibria can emerge in our model as a result of the interactions between endogenous matching and endogenous adoption effort, without relying on increasing returns (e.g., Benhabib and Perli 1994 and Xie 1994) or distortionary taxes (e.g., Bond, Wang and Yip 1996). Third, the creative destruction effects of $\mathrm{R} \& \mathrm{D}$ or technology adoption in the existing literature are usually introduced under either no search friction (e.g., Aghion and Howitt, 1992) or exogenous search frictions (e.g., Laing, Palivos and Wang, 1995b; Boone, 1997; Chen and Shimomura, 1998) in which the equilibrium search and matching process is not explicitly modeled. In our model, such effects are through endogenous market frictions in which the contact rates, the matching surplus and the population division into the matched and the unmatched are all determined in equilibrium. Although our search theoretic approach resembles Bean and Pissarides (1993) and Aghion and Howitt (1994), these two latter studies consider only the consequences of technology advancement on labor market outcomes and do not account for the thick-matching effect on endogenous growth or creative job destruction. Fourth, previous work on industrialization requires a "big push" to bypass a threshold point in order for an economy to take off from a development trap (cf. Murphy, Shelifer and Vishiny, 1989, and Chen and Shimomura, 1998). In our model, as a result of the dynamic interactions between endogenous matching and endogenous technology adoption, a small autonomous technological improvement may be enough to create a large real effect. Finally, similar to most of the R\&D studies, our paper finds that the decentralized solution is generally socially inefficient (see Aghion and Howitt, 1992, and Grossman and Helpman, 1991). The main mechanism underlying this outcome is, however, very different. In our paper, it is the failure to take into account the endogenous matching and job destruction effects on adoption effort that leads to possibilities of under- and over-investment. These channels are novel to the literature. 
The remainder of the paper is organized as follows. Section 2 describes the basic environment of the economy. In Section 3, we prove the existence of a unique steady-state equilibrium with exogenous technology adoption. Section 4 introduces endogenous adoption activity, illustrating the possibility of global and local indeterminacy, characterizing the balanced growth paths satisfying the Correspondence Principle with and without endogenous job destruction, and elaborating on the welfare implications. Finally, Section 5 concludes the paper.

\section{The Environment of the Economy}

Time is continuous. The economy is populated by a continuum of households of unit mass and a continuum of machines. Both households and machine owners face the same discount rate, $r>0$. Each household possesses a unit of productive labor, while each unmatched owner possesses a productive machine. Upon paying a fixed start-up (entry) cost of $\tilde{b}$, an unmatched machine enters the labor market, seeking to match with a search worker to create a positive output, whose present-discounted value is denoted by $\tilde{V}$. Denote the masses of unmatched machines and search workers as $M$ and $N$, respectively. One for one matching implies the equality of the mass of matched workers (employment) and that of matched machines (filled vacancies), denoted $E$. Population identity of workers therefore implies:

$$
E=1-N
$$

\section{A. Technology}

Production is undertaken using the machine-specific technological knowledge $H$, where the growth of the technological knowledge is $\dot{H} / H=\phi>0$. Similar to the public knowledge evolution of Stokey (1991) and the R\&D model of Aghion and Howitt (1992), we consider a simple framework where new technology arrives at a Poisson rate $\lambda$ with an incremental size of $g>0$. Thus, $\phi=\lambda g$ and the stock of technological knowledge at a particular point in time $t$ is given by: $H(t)=H_{0} e^{\lambda g t}$ where $H_{0}$ is normalized to one 
throughout the paper. Due to the nature of perpetual growth in technological knowledge, the economy's present-discounted value of output and other related variables are nonstationary. In the case with endogenous technology adoption, individuals can devote efforts to such an activity and the effective arrival rate is then specified as: $\lambda=\lambda_{0} s$, which is measured by the exogenous arrival factor $\lambda_{0}$ augmented by the endogenous technology adoption effort $s$ exerted by each matched worker-machine pair.

\section{B. Asset Values}

Let $\tilde{J}_{E}$ and $\tilde{\Pi}_{E}$ denote, respectively, a worker's and a machine owner's asset values accrued from a successful match. Similarly, $\tilde{J}_{U}$ and $\tilde{\Pi}_{U}$ denote the corresponding unmatched asset values. Let each worker's flow value of wages upon matching be denoted by $\tilde{W}$. Denote the flow probability for a worker to locate a machine as $\alpha$ and that for a machine to locate a worker as $\beta$. The flow rate of separation of a matched pair of worker and machine (or, shortly, the job destruction rate) is denoted by $\delta$. In the basic model, we will determine the flow contact rates $(\alpha$ and $\beta$ ) in dynamic search equilibrium, while treating the job destruction rate $(\delta)$ as exogenously given. This later assumption will be relaxed in Section 4.E below.

Thus, these asset values (Bellman equations) can be specified as:

$$
\begin{gathered}
r \tilde{J}_{E}=\tilde{W}+\delta\left(\tilde{J}_{U}-\tilde{J}_{E}\right)+\frac{d \tilde{J}_{E}}{d t}, \\
r \tilde{J}_{U}=\alpha\left(\tilde{J}_{E}-\tilde{J}_{U}\right)+\frac{d \tilde{J}_{U}}{d t}, \\
r \tilde{\Pi}_{E}=\tilde{V}-\tilde{W}+\delta\left(\tilde{\Pi}_{U}-\tilde{\Pi}_{E}\right)+\frac{d \tilde{\Pi}_{E}}{d t},
\end{gathered}
$$




$$
r \tilde{\Pi}_{U}=\beta\left(\tilde{\Pi}_{E}-\tilde{\Pi}_{U}\right)+\frac{d \tilde{\Pi}_{U}}{d t},
$$

where $\left(d \tilde{J}_{E} / d t\right) / \tilde{J}_{E}=\left(d \tilde{J}_{U} / d t\right) / \tilde{J}_{U}=\left(d \tilde{\Pi}_{E} / d t\right) / \tilde{\Pi}_{E}=\left(d \tilde{\Pi}_{U} / d t\right) / \tilde{\Pi}_{U}=\lambda g$ both in the steady state with exogenous growth and along a balanced growth path with endogenous growth. Equation (2a) states that the flow matched value of a worker consists of three components: (i) the wage, (ii) the incremental value by changing from matched to unmatched states, and, (iii) the incremental value by remaining in the matched state as a result of the perpetual growth of technological knowledge. As indicated by (2b), the flow unmatched value of a worker includes only the incremental values with and without changing the states. The interpretation of machine owners' asset values follows similarly.

In order to ensure that the ratios of these asset values to the stock of technological knowledge are bounded (such that the steady-state and balanced-growth equilibria are well-defined), we consider a transversality condition (TVC) below:

\section{Condition TVC: $\lambda g<r$.}

This condition implies that the rate of time discount exceeds the rate of growth of the asset values, which is in analogy to the bounded utility assumption imposed in Brock and Gale (1969). Since the conventional Nash bargaining framework applies only to a fixed surplus for any division by the matched party, it is necessary to transform the perpetually growing system into an asymptotically stationary problem. Under Condition TVC, this can be done by dividing each of the perpetually growing variables by $H(t)$. Denote $x=$ $\tilde{x} / H$, where $x=J_{E}, J_{U}, \Pi_{E}, \Pi_{U}, V$ and $W$. Then, the asset value equations (2a)-(2d) can be rewritten, respectively, as: ${ }^{1}$

\footnotetext{
${ }^{1}$ In deriving these expressions, we have used the following relationship: $\quad d \tilde{x} / d t=e^{\lambda \mathrm{gt}}(\dot{x}+x \lambda \mathrm{g})$.
} 


$$
\begin{gathered}
(r-\lambda g) J_{E}=W+\delta\left(J_{U}-J_{E}\right)+\dot{J}_{E}, \\
(r-\lambda g) J_{U}=\alpha\left(J_{E}-J_{U}\right)+\dot{J}_{U}, \\
(r-\lambda g) \Pi_{E}=V-W+\delta\left(\Pi_{U}-\Pi_{E}\right)+\dot{\Pi}_{E}, \\
(r-\lambda g) \Pi_{U}=\beta\left(\Pi_{E}-\Pi_{U}\right)+\dot{\Pi}_{U} .
\end{gathered}
$$

\section{Matching and Evolution of Population}

Let the matching technology $q=q_{\mathrm{o}} Q(N, M)$ be a well-defined function of the masses of the matching parties, $N$ and $M$, where $q_{\mathrm{o}}>0$ represents the efficacy of the matching technology. An increase in the matching parameter $q_{\mathrm{o}}$ captures a reduction in the severity of market frictions. For example, a higher $q_{\mathrm{o}}$ may be a consequence of the establishment of an employment center, or better news and media to the public. Following Diamond (1982b) and Laing, Palivos and Wang (1995a), we assume $Q$ is increasing and strictly concave in each argument ( $Q_{N}>0>Q_{N N}, Q_{M}>0>Q_{M M}$ ), satisfying the constant-returns-to-scale property, the Inada conditions, $\lim _{N \rightarrow 0} Q_{N}(N, M)=\infty, \lim _{N \rightarrow \infty} Q_{N}(N, M)=0, \lim _{M \rightarrow 0} Q_{M}(N, M)=\infty$ and $\lim _{M \rightarrow \infty} Q_{M}(N, M)=0, \quad$ and the boundary conditions, $Q(N, 0)=Q(0, M)=0$.

Since a vacancy is filed by one and only one worker, the evolution equations of the population of the unemployed and employed pools are given by,

$$
\begin{gathered}
\dot{N}=\delta E-\alpha N, \\
\dot{E}=\alpha N-\delta E=\beta M-\delta E,
\end{gathered}
$$

Equation (4a) implies that a net outflow from the unemployed pool leads to an increase in the mass of search workers. Similarly, (4b) specifies that a net inflow of either workers or machines into the employed pool results in a higher mass of employed worker-machine pairs. 


\section{Nash Bargaining}

Given the risk neutral nature of workers and machines, a simple cooperative Nash bargaining rule for instantaneous negotiations: the surplus accrued from a successful match between a search worker and a vacancy is equally divided between the two parties. $^{2}$ Though nothing essential hinges on the symmetry assumption of the Nash bargaining rule, it simplifies the mathematical expressions. To be more specific, the symmetric Nash bargaining rule is:

$$
\tilde{J}_{E}-\tilde{J}_{U}=\tilde{\Pi}_{E}-\tilde{\Pi}_{U}>0
$$

or, after transformation,

$$
J_{E}-J_{U}=\Pi_{E}-\Pi_{U}>0 .
$$

That is, the incremental values of matching to workers and to machines are identical. The surplus is assumed positive to rule out the uninteresting degenerate (no-action) equilibrium.

\section{E. The Dynamical System}

The dynamical system can be summarized by the evolution of asset values and population masses.

Denote $J \equiv J_{E}-J_{U}$ as the value of matching surplus facing each worker. Utilizing (3a) and (3b) and substituting (1) into (4a), we obtain:

$$
\begin{gathered}
\dot{J}=(\alpha+\delta+r-\lambda g) J-W . \\
\dot{N}=\delta E-\alpha N=-(\alpha+\delta) N+\delta
\end{gathered}
$$

Notably, by the symmetric Nash bargaining rule (which holds for all t), the evolution of the value of matching surplus facing each machine, $\Pi \equiv \Pi_{E}-\Pi_{U}$, and the evolution of $J$ are linearly dependent.

\footnotetext{
${ }^{2}$ Indeed, this equal division rule is obtained from maximization of the joint objective function $\left(\tilde{J}_{E}-\tilde{J}_{U}\right)^{1 / 2}\left(\tilde{\Pi}_{E}-\tilde{\Pi}_{U}\right)^{1 / 2}$.
} 
Moreover, (4b) implies that the evolution of the unemployed and employed population masses, $N$ and $E$, are also linearly dependent. To complete the dynamical system, one must fully specify $W, \alpha$ and $s$ as stationary functions of $N$ and $J$. Such an analysis is quite complex, so a discussion will be relegated to Section 4.D below.

\section{Exogenous Growth Equilibrium with Exogenous Technology Adoption}

To begin, we consider a simple case with exogenous technology adoption. An immediate consequence is that the rate of the economy's growth is exogenous. Under this structure, we can apply the symmetric Nash bargaining rule to obtain the wage offer function and then utilize the steady-state matching and equilibrium entry conditions to solve for the contact rate functions. This is a useful first step toward determining the endogenous effort function of technology adoption in a backward-induction manner described as in Section 4 below.

\section{A. Transformed Asset Values}

Should the contact rate $\alpha$ be constant, one can easily see from (6a) and (6b) that $N$ adjusts gradually to the steady-state equilibrium value, whereas provided that Condition TVC is met, $J$ must jump instantaneously to the steady state, in which all asset values grow at a constant exogenous rate $\lambda \mathrm{g}$. Thus, in steady-state equilibrium with exogenous growth, the transformed asset values are all constant over time (i.e., $\left.\dot{J}_{E}=\dot{J}_{U}=\dot{\Pi}_{E}=\dot{\Pi}_{U}=0\right)$, whereas both unemployed and employed masses $(N$ and $M)$ are stationary. From (3a) and (3b), we then obtain:

$$
\begin{aligned}
& J_{U}=\frac{\alpha}{r-\lambda g+\delta+\alpha} \frac{W}{r-\lambda g}, \\
& J_{E}=\frac{r-\lambda g+\alpha}{r-\lambda g+\delta+\alpha} \frac{W}{r-\lambda g} .
\end{aligned}
$$

Therefore, an increase in flow wages or worker's contact rate increases both the employed and unemployed 
values of workers. It is also clear from (7a) and (7b) that Condition TVC is sufficient (but not necessary) to guarantee $J=J_{E}-J_{U}>0$ and thus the steady-state equilibrium, if it exists, is non-degenerate.

As illustrated by Pissarides (1985) and Laing, Palivos and Wang (1995a), we assume that $\Pi_{U}$ in competitive market is treated as parametric by unmatched machines and its value is determined by the search market in equilibrium. From (3c) in the steady state, taking $\Pi_{U}$ as given, we get:

$$
\Pi_{E}=\frac{V-W+\delta \Pi_{U}}{r-\lambda \mathrm{g}+\delta} .
$$

This implies that the matched value of machines depends positively on its flow return, $V-W$, as well as the reservation (or unmatched) value, $\Pi_{U}$. An increase in the job destruction rate $(\delta)$ reduces both the matched and the unmatched asset values of workers by raising future discounting - a higher job destruction rate gives rise to a greater likelihood of separation in the future, thereby adding to the subjective rate of discounting. On the contrary, an increase in the rate of technological knowledge growth enhances future values and can thus be regarded as a negative discounting factor. For future references, we will call the term, $r-\lambda g+\delta>0$, as the effective discount rate. A higher rate of exogenous technology growth raises unmatched workers' values via (i) a reduction in the effective discounting rate, which will be referred to as the capitalization effect (cf. Aghion and Howitt, 1994), and, (ii) an increase in the stock value of the wage, $W /(r-\lambda g)$, which will be called the direct wage effect (cf. Laing, Palivos and Wang, 1995a). While rapid growth affects a worker's matched value positively through the effective discounting, it also generates a negative effect due to an encouragement toward waiting for a larger reward from enhanced future knowledge (i.e., the waiting effect). Of course, there is a positive direct wage effect, which can be shown to dominate the waiting effect and hence a higher rate of exogenous growth results in an unambiguous positive effect on the matched value. $^{3}$ In response to a higher unmatched value, a machine owner's reservation value increases, as does the

${ }^{3}$ This can be seen by rewriting (7b) as: $\quad J_{E}=\frac{1}{r-\lambda n+\delta+N}\left|1+\frac{\alpha}{r-\lambda n}\right| W$. 
matched value.

\section{B. The Wage Offer}

Using (5b) and equations (7a), (7b) and (8), we can derive the wage offer function:

Lemma 1: (Wage Offer) The wage offer function $\mathrm{W}\left(\alpha, \lambda \mathrm{g}, V, \delta, \Pi_{U}\right)$ determined in a symmetric Nash bargain between a search worker and an unmatched machine is given by:

$$
W\left(\alpha, \lambda g, V, \delta, \Pi_{U}\right)=\frac{r-\lambda g+\delta+\alpha}{2(r-\lambda g+\delta)+\alpha}\left[V-(r-\lambda g) \Pi_{U}\right]
$$

which satisfies: $\partial W / \partial \alpha>0, \partial W / \partial(\lambda \mathrm{g})>0, \partial W / \partial V>0, \partial W / \partial \delta<0, \partial W / \partial \Pi_{U}<0$.

Intuitively, an increase in the worker's contact rate $(\alpha)$ strengthens workers' bargaining power, thereby leading to a higher wage offer unambiguously - this will be referred to as the thick-matching effect. There are, however, conflicting effects of technology growth $(\lambda \mathrm{g})$ on the wage offer in a way similar to the discussion on workers' matched value: (i) a positive capitalization effect (the denominator of the first term on the righthand side of equation (9)), (ii) a negative waiting effect (the numerator of the first term on the righthand side), and, (iii) a positive net productivity effect (the second term on the righthand side). Since the positive capitalization effect dominates the negative waiting effect, the net effect of technological knowledge growth on the wage turns out to be positive. ${ }^{4} \quad$ As the job destruction increases, workers face a negative capitalization effect and a positive waiting effect. By similar arguments (i.e., the capitalization effect dominates the waiting effect), job separation reduces the wage offer unambiguously. Finally, an increase in

${ }^{4}$ Precisely, define $\quad \omega \equiv \frac{r-\lambda g+\delta+\alpha}{2(r-\lambda g+\delta)+\alpha} \quad$ where $\quad \frac{d \omega}{d(\lambda g)}=\frac{\alpha}{[2(r-\lambda g+\delta)+\alpha]^{2}}>0$ 
the machine owner's unmatched value raises his threat point and thus suppresses the wage offer.

Notably, both economic growth and job separation rates are important determinants of the wages. This contrasts with the traditional wage bargaining literature such as Diamond (1982b) and Pissarides (1985). The influence of economic growth on wages is considered by Laing, Palivos and Wang (1995a) and Bean and Pissarides (1993), whereas Mortensen and Pissarides (1994) examine the job separation effect. Although Aghion and Howitt (1994) study both channels, they focus primarily on the capitalization effect without accounting for thick-matching or waiting effects.

\section{Equilibrium Entry}

For any given values of $\left\{\alpha, \lambda \mathrm{g}, V, \delta, \Pi_{U}\right\}$, the wage offer function and the steady-state version of (3d) can be substituted into (8) to yield the following equilibrium condition on machine owners's entry:

$$
\Pi_{U}=\frac{\beta}{r-\lambda g+\delta+\beta}\left[\frac{V-W\left(\alpha, \lambda g, V, \delta, \Pi_{U}\right)}{r-\lambda g}\right]=b .
$$

Intuitively, if the incumbent machine owners earn a positive profit (ex ante), new machine owners will enter, which lowers the flow probability for a machine to locate a worker and hence reduces the expected profit (measured by the unmatched value net of the entry cost). This process continues until the expected profit is driven down to zero.

Equation (10) establishes a relationship between the two endogenous contact rates, $\alpha$ and $\beta$. This free entry relationship, referred to as the $\boldsymbol{F E}$ locus, can be best understood in the following form, obtained by plugging (9) into the second equality of (10):

$$
\alpha=-2(r-\lambda g+\delta)+\frac{r-\lambda g+\delta}{b}\left(\frac{V}{r-\lambda g}\right) \frac{\beta}{r-\lambda g+\delta+\beta}
$$

It is trivial to show that the FE locus is upward-sloping in $(\alpha, \beta)$-space with a positive vertical intercept and 
with $\beta$ approaching infinity at a finite value of $\alpha .^{5}$ Given a particular value of the machine's contact rate $\beta$, an increase in the rate of economic growth $g$ results in a higher expected profit and encourages machine entry, thus raising the worker's contact rate $\alpha$. This explains why the slope of the FE locus is positive. Notice also that an increase in the job separation rate $\delta$ discourages machine entry, which subsequently lowers the worker's contact rate.

By substituting (10) $\left(\Pi_{U}=b\right)$ into (9), we get

$$
W=\frac{r-\lambda g+\delta+\alpha}{2(r-\lambda g+\delta)+\alpha}[V-(r-\lambda g) b]
$$

Thus, to avoid degenerate solution, we consider the case where the value of output from a match exceeds the fixed cost of entry:

Condition V: $\frac{\mathrm{V}}{\mathrm{r}}>b$.

This inequality shares great similarity with the positive growth condition imposed in the endogenous growth literature, frequently referred to as the Jones-Manuelli (1990) condition.

\section{Steady-State Matching}

In steady state equilibrium, the outflows and inflows from and to the unemployed pool must be equal. That is, (4a) holds with $\dot{N}=0$, which leads to,

$$
\alpha N=\delta E .
$$

${ }^{5}$ The vertical intercept is given by $\beta_{0}=\frac{2(r-\lambda g+\delta) b}{\frac{V}{r-\lambda g}-\frac{1-2(r-\lambda g+\delta)}{(r-\lambda g+\delta)}+b}$ and $\beta$ approaches infinity as $\alpha$ approaches $\quad \alpha^{\max }=\frac{r-\lambda g+\delta}{r-\lambda g} \frac{V}{b}-2(r-\lambda g+\delta)$. 
Moreover, the steady-state flow matches measured from both the worker and the machine pools must be identical and thus (4b) with $\dot{E}=0$ yields,

$$
\alpha N=\beta M=q_{0} Q(N, M)
$$

This equation implies that the rates of matches increase in the masses of both parties. We can now utilize the constant-returns-to-scale property of $Q(N, M)$ to rewrite (14) as:

$$
\beta=q_{0} Q\left(\frac{\beta}{\alpha}, 1\right)=\beta\left(\alpha ; q_{0}\right) .
$$

in which $\beta_{\alpha}<0$ and $\beta_{q_{0}}>0$. Equation (15) gives the Beveridge curve relationship in terms of contact rates, which is referred to as the $\boldsymbol{B C}$ locus. This locus is negatively sloped in $(\alpha, \beta)$-space, with both horizontal and vertical axes as asymptotes.

E. Steady-State Exogenous-Growth Equilibrium

Equations (11) and (15) can be used to solve the steady-state equilibrium contact rates $\alpha^{*}$ and $\beta^{*}$. As shown in Figure 1, such a solution exists under the Inada conditions imposed on the matching technology. Utilizing (1) and (14), we obtain equilibrium matched and unmatched masses:

$$
E^{*}=\frac{\alpha^{*}}{\alpha^{*}+\delta}, \quad N^{*}=1-E^{*}=\frac{\delta}{\alpha^{*}+\delta}, \quad M^{*}=\frac{\alpha^{*}}{\beta^{*}} N^{*}=\frac{\alpha^{*}}{\beta^{*}} \frac{\delta}{\alpha^{*}+\delta} .
$$

Thus, equilibrium employment (or, the equilibrium mass of matched worker-machine pairs) $E^{*}$ is positively related to the worker's contact rate. While the equilibrium mass of search workers $N^{*}$ depends negatively on the worker's contact rate, the equilibrium mass of vacant machines $M^{*}$ depends negatively on the machine's contact rate but positive on the worker's.

We are now ready to define and prove the existence of the steady-state equilibrium. 
Definition 1: A steady-state exogenous-growth equilibrium is a tuple $\left\{W^{*}, \alpha^{*}, \beta^{*}, \Pi_{U}{ }^{*}, E^{*}, N^{*}, M^{*}\right\}$ of positive values satisfying:

(i) symmetric Nash bargain: (5b);

(ii) free entry: (10);

(iii) steady-state matching: (13) and (14);

(iv) population identity: (1).

From the discussion above, the steady-state exogenous-growth equilibrium $\left\{W^{*}, \alpha^{*}, \beta^{*}, \Pi_{U}{ }^{*}, E^{*}, N^{*}\right.$, $\left.M^{*}\right\}$ solves equations (1), (5b), (10), (13) and (14) where both (10) and (14) contain two equilibrium relationships. Equivalently, we can use (11), (12), (15) and (16) to obtain the equilibrium solution in a recursive manner. More precisely, $\Pi_{U}{ }^{*}=b, \alpha^{*}$ and $\beta^{*}$ are determined by (11) and (15), $W^{*}$ by (12) and $E^{*}$, $N^{*}$ and $M^{*}$ by (16). This leads to:

Theorem 1: (Existence and Uniqueness of Steady-State Exogenous-Growth Equilibrium) Under Conditions TVC and V, there exists a unique nondegenerate steady-state exogenous-growth equilibrium.

\section{Technology Adoption}

In this Section, we extend the basic environment to allow for endogenous technology adoption in an endogenous growth setting. This is done in three steps: (i) the adoption effort is determined by individual optimization; (ii) the job destruction rate is allowed to depend positively on the rate of endogenous technology arrival; and, (iii) the rate of technological knowledge growth is endogenized following the Romer (1990) convention in that the society's average adoption effort influences the rate of technological knowledge growth. These considerations not only permit endogenous growth but enable us to examine the creative destruction feature of new technologies as described by Aghion and Howitt (1992).

Specifically, let $C(s)$ be the total cost associated with an adoption effort level $s$, where $C_{s}>0$ 
and $C_{s s}>0$. In response to a higher rate of adoption of new technologies (an increase in $\lambda=\lambda_{0} s$ ), existing jobs are detached at a more rapid rate (i.e., the endogenous job destruction effect). Thus, we can specify: $\delta=\delta_{0}$ $\Delta(\lambda)$, where $\Delta(0)=1, \Delta_{\lambda}>0, \Delta_{\lambda \lambda}>0$ and $\delta_{0}>0$ measures the rate of exogenous job destruction. Further assume that the rate of technology growth (excluding the arrival factor) is enhanced by the society's average adoption effort $(\bar{s})$, that is, $\mathrm{g}=\mathrm{g}_{\mathrm{o}} G(\bar{s})$, where $G(0)=1, G_{\bar{s}}>0, G_{\bar{s} \bar{s}}<0$ and $\mathrm{g}_{\mathrm{o}}>0$ measures the rate of exogenous knowledge growth. By symmetry, we have $\bar{s}=s$ in equilibrium.

\section{A. Individual Optimization}

An individual's technology adoption is determined by maximizing the present-discounted value net of the adoption cost: ${ }^{6} \quad \operatorname{Max}_{\{s\}} J_{U}(0) \sum_{i=0}^{\infty} \frac{\left(\lambda_{0} s\right)^{i} e^{-\lambda_{0} s}}{i !}(1+\mathrm{g})^{i}-C(s)$. Substituting (12) into (7a) with $t=$ 0 and using the fact that the summation term in the objective is $e^{\lambda_{0} s g}$, the individual optimization problem can thus be rewritten as:

$$
\underset{\{s\}}{\operatorname{Max}}\left\{\frac{\alpha^{*}(\mathrm{~g}, \delta)}{2[r-\lambda s \mathrm{~g}+\delta]+\alpha^{*}(\mathrm{~g}, \delta)}\left[\frac{V}{r-\lambda \mathrm{g}}-b\right]\right\} e^{\lambda_{0} s g}-C(s),
$$

where the value in the large brackets is $J_{U}(0)$.

Importantly, an individual is atomistic and hence does not take into account the effect of his behavior on the market value of $J_{U}(0)$. Denote the marginal benefit of technology adoption as $B(s)$. The first-order condition for an individual's choice of $s$ becomes: $B(s)=J_{U}(0) e^{\lambda_{0} s \mathrm{~g}} \lambda_{0} \mathrm{~g}=C_{s}(s)$, or,

${ }^{6}$ Implicitly, we regard matched worker-machine pairs as "firms" and workers as "entrepreneurs," mastering the technology adoption decision. This is a sensible setup because each machine owners' ex ante profit is zero by free entry and thus, maximization of the corresponding worker's objective is equivalent to joint optimization. Should one treat machine owners as entrepreneurs, the term $J_{U}(0)$ in the objective needs to be replaced by the matching surplus $\Pi_{E}(0)-\Pi_{U}(0)$, as the competitive value of $\Pi_{U}(0)$ is simply pinned down by the fixed entry cost. Then, (5b), (7a), (7b) and (12) imply: $\Pi_{E}(0)-\Pi_{U}(0)=[(r-\lambda \mathrm{g}) / \alpha] J_{U}(0)$. Thus, one can easily show that our analysis remains valid and the main conclusions are qualitatively unchanged. We prefer the former setup as the use of ex ante unmatched value is more consistent with the concept of the ex ante technology adoption decision. 


$$
B(s)=\frac{\alpha^{*}\left(g(s), \delta\left(\lambda_{0} s\right)\right)\left[\frac{V}{r-\lambda_{0} s g(s)}-b\right]}{2\left[r-\lambda_{0} s g(s)+\delta\left(\lambda_{0} s\right)\right]+\alpha^{*}\left(g(s), \delta\left(\lambda_{0} s\right)\right)} e^{\lambda_{0} s g(s)} \lambda_{0} g(s)=C_{s}(s) .
$$

where we have imposed the equilibrium condition $\bar{s}=s$.

Define $B_{0}=B(0)=\frac{\alpha^{*}\left(g_{0}, \delta_{0}\right)(V / r-b) \lambda_{0} g_{0}}{2\left(r+\delta_{0}\right)+\alpha^{*}\left(g_{0}, \delta_{0}\right)}$ and $C_{0}=C_{s}(0)$. It is reasonable to assume the longrun destruction effect of the adoption effort via the flow separation rate to be sufficiently small so that $J_{U}(0)$ is increasing in $s$. This, together with the strict convexity property of the adoption cost, implies both $B(s)$ and $C_{s}(s)$ are increasing in $s$. However, $B(s)$ can be very nonlinear in $s$. Let $s^{\max }$ solve $\lambda_{0} s \mathrm{~g}(s)=r$ and hence $\lim _{s \rightarrow s^{\max }} B(s)=\infty$. For illustrative purposes, we consider three cases (see Figure 2). In Case I, $B(s)$ and $C_{s}(s)$ have a unique intersection at $s^{*}>0$, where the $B(s)$ locus cuts the $C_{s}(s)$ locus from above and $\lim _{s \rightarrow s^{\max }}\left[B(s)-C_{s}(s)\right]<0$. Case II displays the possibility of the co-existence of a corner and a stable interior solution, $s_{L}{ }^{*}=0$ and ${s_{H}}^{*}>0$, with the second-order condition satisfied (accompanied by an unstable interior solution $s_{M}{ }^{*}$ violating the Correspondence Principle). This requires the $B(s)$ locus to cut the $C_{s}(s)$ locus twice with $B_{0}<C_{0}$ and $\lim _{s \rightarrow s^{\max }}\left[B(s)-C_{s}(s)\right]<0 .{ }^{7}$ By similar arguments, there may be two stable interior solutions, $s_{L}{ }^{*}>0$ and $s_{H}{ }^{*}>0$ (associated with an unstable solution, $s_{M}{ }^{*}$ ) as delineated by Case III. In this case, the $B(s)$ locus cuts the $C_{s}(s)$ locus three times, satisfying the two boundary conditions: $B_{0}>C_{0}$ and $\lim _{s \rightarrow s^{\max }}\left[B(s)-C_{s}(s)\right]<0$. Of course, it is possible that more than two stable interior solutions may arise, depending on the slopes and curvatures of the $B(s)$ and $C_{s}(s)$ loci. ${ }^{8}$

For any cases satisfying the Correspondence Principle, we can characterize the technology adoption

${ }^{7}$ Multiplicity occurs when $C_{0}$ is not too large and $C_{s}$ is not too steep. By the Approximation Theorem, one may easily find examples with both $B(s)$ and $C_{s}(s)$ as third-order polynomial functions of $s$ to satisfy the boundary conditions and to intersect each other twice.

${ }^{8}$ Should one assumes instead $\lambda(s)$ is a strictly concave function with $\lim _{s \rightarrow \infty} \lambda(s) g(s)<r$, the adoption effort is no longer subject to an upper bound, $s^{\max }$. For instance, one may have the following specification: $\lambda(s) \mathrm{g}(s)=R-\left(R-R_{0}\right) e^{-\epsilon s}$, where $0<R_{0}<R<r$ and $\epsilon>0$. Under this setup, all three cases are still possible to arise and thus our main conclusions remain unchanged. 
effort as follows:

Lemma 2: (Technology Adoption Effort) Under the Correspondence Principle, the technology adoption effort function $s=s\left(\alpha, \lambda_{0}, \delta_{0}, b\right)$ satisfies: $\partial s / \partial \alpha>0, \partial s / \partial \lambda_{0} \frac{>}{<} 0, \partial s / \partial \delta_{0}<0, \partial s / \partial b<0$.

An increase in the worker's contact rate $(\alpha)$ raises the expected value and thus encourages technology adoption. Conversely, an increase in either the rate of exogenous job destruction or the cost of machine entry discourages the technology adoption activity. The effect of the rate of exogenous technology arrival is, however, ambiguous, depending on the magnitudes of the positive knowledge growth effect (via the term $e^{\lambda_{0} s g(s)} \lambda_{0} g(s)$ in the marginal benefit function) and the positive capitalization effects (via the effective discount rate in $J_{U}(0)$ ) versus the negative endogenous destruction effect (via $\delta$ ). Finally, we note that given the Poisson process, the average length of technology arrivals can be measured by $L=1 / \lambda=1 /\left(\lambda_{0}\right.$ $s)$. An increase in $L$ implies longer technology diffusion. Thus, the higher the adoption effort is exerted, the shorter the technology diffusion will be.

Our determination of technology adoption contrasts sharply with the existing literature. In Parente and Prescott (1994) and Parente (1995), technology adoption is modeled based on exogenous barriers. Recently, Parente and Prescott (1999) endogenize such barriers via the monopoly rent-seeking behavior of producers. While Chen and Shimomura (1998) allow search frictions to influence adoption effort under a search intensity setup, our paper considers both search and entry frictions as determinants for technology diffusion in a dynamic general-equilibrium search framework.

B. Balanced Growth Equilibrium With Endogenous Technology Adoption

We are now prepared to define a balanced growth equilibrium with endogenous technology adoption:

Definition 2: A balanced growth equilibrium with endogenous technology adoption is a tuple $\left\{W^{*}, \alpha^{*}\right.$, $\left.\beta^{*}, \Pi_{U}{ }^{*}, E^{*}, N^{*}, M^{*}, s^{*}\right\}$ of positive values satisfying (i)-(iv) as described in Definition 1 and, in addition, 
Obviously, by Theorem 1 and Lemma 2, a balanced growth equilibrium with endogenous adoption effort exists. With endogenous technology adoption, multiplicity in the form of global indeterminacy may arise. Notably, in contrast with the conventional literature where multiplicity is a result of increasing returns in production, multiple equilibria emerge in our model due mainly to the interactions between endogenous matching and endogenous technology adoption in the absence of increasing returns. In particular, within the search and matching framework, the behaviors of workers and machine owners are strategic complements. Should workers anticipate higher returns on technology adoption, the net matching surplus would rise, leading to higher wages as well as more flow matches. As the ex ante expected value increases, adoption returns would turn out to be higher, thereby fulfilling the original prophecies.

In contrast with the stationary state search literature (e.g., Diamond, 1982a; Chen, 1995) or the creative destruction literature with limit cycles (e.g., Aghion and Howitt, 1992), multiple equilibria in our model are associated with different balanced growth paths. That is, different equilibria feature different levels of adoption effort as well as different rates of economic growth. In this regard, our finding resembles that of two recent branches of research: (i) Aghion and Howitt (1994), Laing, Palivos and Wang (1995b) and Chen and Shimomura (1998) where multiplicity is a result of coordination failure with endogenous search intensity; (ii) Laing, Palivos and Wang (1995a) where multiplicity occurs due to interplays of endogenous learning and endogenous matching. Yet, the underlying mechanism driving the global indeterminacy result in our model is different from these previous studies.

In order to highlight the role of market frictions, we examine a special case where there is no search or entry friction, i.e., $\alpha$ goes to infinity and $b$ goes to zero. Such a balanced growth equilibrium is indicated by point $\mathrm{E}$ in Figure 3. As we begin to introduce market (search and entry) frictions, it is equivalent to the consideration that $\alpha$ reduces (from infinity) and $b$ raises (from zero). This is then represented by a downward shift of the $B(s)$ locus, resulting in a new balanced growth path indicated by $\mathrm{E}^{\prime}$. Thus, it is clear 
that the optimal technology adoption effort in the presence of market frictions is lower than that without. An immediate consequence is that market frictions lengthen technology diffusion. Thus, we can conclude:

Theorem 2: (Existence and Multiplicity of Balanced Growth Paths) Under the assumptions described as in Theorem 1 and Lemma 2, a balanced growth equilibrium with endogenous adoption effort exists but multiplicity may emerge. The presence of search and entry frictions results in a lower technology adoption effort and a longer technology diffusion.

The fast-growing Taiwan economy may serve as a good example for illustrating the relation between search frictions and technology diffusion. Taiwan's industrial structure is characterized by a large fraction of small and medium size firms (e.g., Amsden, 1991) and by efficient labor market (e.g., Field, 1985). These two features imply a smaller search friction for firms and workers in Taiwan, compared to many other developing countries. As a result, firms in Taiwan are able to adopt more advanced technology at a faster rate, thus shortening technology diffusion and enhancing economic growth. Similar evidence can be found in the US. Mansfield (1969), for example, studies the diffusion of machine tools with numerical control in the U.S. and concludes that innovations tend to spread more rapidly in less concentrated industries which suffer less entry barriers.

\section{Comparative Statics in the Absence of Endogenous Job Destruction}

Using Figure 4, we can examine the long-run effects of an exogenous growth advancement. To begin, we assume that the endogenous separation effect is negligible. In this case, an increase in the rate of exogenous technology arrival $\left(\lambda_{0}\right)$ or average growth $\left(g_{\mathrm{o}}\right)$ shift FE shifts right, thus raising the worker's contact rate $\left(\alpha^{*}\right)$ and lowering the machine's contact rate $\left(\beta^{*}\right)$. Form (15), both the employment $\left(E^{*}\right)$ and the mass of unmatched machines $\left(M^{*}\right)$ increase whereas the mass of search workers reduces $\left(N^{*}\right)$. These results together with Lemma 1 imply that the wage rises, as does the present-discounted value of the wage flow $\left(\frac{W}{r-\lambda g}\right)$. Moreover, there are two additional positive effects via the effective discounting and the worker's 
contact rate $\alpha^{*}$ (i.e., capitalization and thick-matching effects). The resultant increase in $J_{U}(0)$, therefore, encourages the technology adoption effort $\left(s^{*}\right)$. These can be summarized by:

Proposition 1: (Effects of Exogenous Technology Arrival and Exogenous Growth) Assume that the endogenous separation effect is negligible. An increase in the rate of exogenous technology arrival or average growth increases the worker's contact rate, the wage, the adoption effort, the employment and the mass of unmatched machines, but decreases the machine's contact rate and the mass of search workers.

The Taiwan economy may be used as an example to illustrate this proposition as well. Using the 1981, 1986 and 1991 Manufacturing Census data in Taiwan, Aw, Chen and Roberts (1997) find that Taiwan's manufacturing output grew very rapidly in the 1980s, at an average annual rate of 11.4 percent. During the same period, there was numerous machine entry. Their results suggest that the most important contribution to the 1991 Taiwanese industrial production was from the 1987-1991 entrant cohort. In chemical industry, for example, 40.1 percent of the 1991 output was contributed by the 1987-1991 entrant cohort and 29.2 percent by the 1982-1986 entrant cohort; in textile industry, the comparable figures were 33.4 percent and 24.2 percent, respectively. They also find that new entrants have higher productivity which made significant contribution to industrial growth. The evidence suggests a positive relationship between output growth/technical progress and the mass of unmatched machines, lending empirical support to findings in our Proposition.

In the absence of the endogenous job destruction, if the rate of exogenous technology arrival or average growth increases, not only do those employed (E) gain higher wages but a fraction of the originally unemployed (U) find employment and start earning positive wages (see Figure 5). While the wage dispersion between the employed and the "long-term" unemployed (UU) widens, that between the employed and the newly employed (UE) narrows to zero. This therefore leads to the following: 
Proposition 2: (Wage Dispersion) Under the assumptions as described in Proposition 1, an increase in the rate of exogenous technology arrival or average growth has an ambiguous effect on the overall wage dispersion, depending on the relative magnitudes of the conflicting forces from the long-term unemployed and the newly employed.

Despite the absence of endogenous job destruction, multiple equilibria are still present. Figure 6 displays the case of three multiple balanced growth paths in which an increase in the rate of exogenous technology arrival or average growth may improve the initially unique low-growth equilibrium L to reach a high-growth equilibrium $\mathrm{H}^{\prime}$. Notice that this result differs from Murphy, Shelifer and Vishiny (1989) and Chen and Shimomura (1998) where a "big push" is required to bypass the threshold point in order for a big forward leap. In our paper, even with a small shift in the marginal benefit $B(s)$ locus, it is possible to generate a big forward leap since there is no threshold required for such jump to occur. That is, we have:

Proposition 3: (Big Push) Under the assumptions as described in Proposition 1, a small increase in the rate of exogenous technology arrival or average growth may create a large growth effect leading an economy from a low-tech, low-growth to a high-tech, high-growth balanced growth equilibrium.

\section{Transitional Dynamics}

We now examine the dynamic property of the underlying economy. Substituting the wage expression (12) into the evolution equation of the value of each worker's matching surplus (6a) yields:

$$
\dot{J}=(\alpha+\delta+r-\lambda g) J-\frac{r-\lambda g+\delta+\alpha}{2(r-\lambda g+\delta)+\alpha}[V-(r-\lambda g) b]
$$

The equation system (6b) and (19), together with the evolution equations of $\alpha$ and $s$, determines equilibrium dynamics. Since a complete characterization of such high-order nonlinear transitional dynamics is not the main purpose of the present work, we focus on a special case leading to interesting results, which are general 
enough to capture the main features of the original system. Consider,

Condition D: $\delta=\delta_{0}, \alpha=\alpha(N)$ and $s=s(J)$, with $\alpha_{N}<0$ and $s_{J}>0$.

That is, we assume exogenous job separation and ignore the general equilibrium effects of endogenous adoption effort on worker's contact rates and those of the masses of unemployed workers on technology adoption. ${ }^{9}$ It is clear that a larger population of unemployed workers reduces each worker's flow contact rate (i.e., the crowding-out effect), whereas higher matching surpluses induce greater adoption effort (i.e., the adoption-incentive effect). In this case, we can derive the Jacobian matrix $A$ with respect to $(N, J)$ as follows:

$$
A=\left(\begin{array}{ll}
a_{11} & a_{12} \\
a_{21} & a_{22}
\end{array}\right)
$$

where $\quad a_{11}=-(\alpha+\delta)+N\left(-\alpha_{N}\right), \quad a_{12}=0, \quad a_{21}=\left(-J+\frac{\partial W}{\partial \alpha}\right)\left(-\alpha_{N}\right)=-\left(-\alpha_{N}\right) J\left[\frac{r-\lambda g+\delta+\alpha}{2(r-\lambda g+\delta)+\alpha}\right]<0 \quad$ and $a_{22}=-\left[J \frac{d(\lambda g)}{d s}+\frac{d W}{d s}\right] s_{J}+(\alpha+\delta+r-\lambda g)$

The trace of the Jacobian matrix is $\operatorname{Tr}(A)=a_{11}+a_{22}$ and the determinant is $\operatorname{Det}(A)=a_{11} a_{22}$. Since $\partial W / \partial \alpha>0, d(\lambda \mathrm{g}) / d s>0, d W / d s>0, \alpha_{N}<0$ and $s_{J}>0$, neither $a_{11}$ nor $a_{22}$ has an unambiguous sign. As a consequence, we may have three possibilities: (i) when $a_{11}>0$ and $a_{22}>0$, the balanced growth equilibrium is a source and the dynamical system is locally unstable; (ii) when $a_{11} a_{22}<0$, the balanced growth equilibrium is a saddle along which the transition is locally determinate; and, (iii) when $a_{11}<0$ and $a_{22}<0$, the balanced growth equilibrium is a sink in which there is a continuum of transition paths converging to the

${ }^{9}$ While the specification of $\alpha$ is easily understood, that of $s$ can be seen by using (7a) and (7b) to rewrite (18) as: $J \frac{\alpha(g(s), \delta)}{r-\lambda_{0} s g(s)} e^{\lambda_{0} s(s)} \lambda_{0} g(s)=C_{s}(s)$, which can be inverted around the stable balanced growth paths to yield the implicit function $s=s(J)$. 
balanced growth path (i.e., local indeterminacy).

In the absence of matching externality and endogenous technology adoption, one can see clearly that $\alpha_{N}=s_{J}=0$ and hence $a_{11}<0<a_{22}$, implying saddle-path stability. In the case where the crowding-out effect is sufficiently strong and the adoption-incentive effect sufficiently weak (so that $a_{11}>0$ and $a_{22}>0$ ), we have dynamic local instability. When the adoption-incentive effect is dominating and the negative matching externality from crowding-out is negligible (so that $a_{11}<0$ and $a_{22}<0$ ), local indeterminacy emerges in which economies with similar initial conditions (or histories) may follow very different transition paths toward balanced growth. Similar to the global indeterminacy result, it is again the dynamic interactions between matching and endogenous technology adoption that generate the possibility of local indeterminacy. Summarizing,

Proposition 4: (Transitional Dynamics and Local Indeterminacy) Under the assumption described as in Proposition 1 and Condition D, a balanced growth equilibrium may be a source, a saddle or a sink, depending crucially on the magnitudes of crowding-out versus adoption-incentive effects.

Interestingly, local indeterminacy has been found in canonical growth models with increasingreturns-to-scale technologies, positive knowledge spillovers or distortionary taxes (cf. Benhabib and Perli, 1994; Xie, 1994; Bond, Wang and Yip, 1996). In non-Walrasian search theoretic models, we are only aware of the study by Chen and Shimomura (1998), obtaining multiple transition paths under an increasing-returnsto-scale production technology. In our paper, however, local indeterminacy arises in the absence of increasing returns, positive spillovers or distortionary taxes. It is also noteworthy that in the general case with a completely specified dynamical system $(4 \times 4)$ and/or with endogenous job destruction, the underlying forces that drive local indeterminacy, namely the dynamic interactions between matching and endogenous technology adoption, are still present. Therefore, Proposition 4 remains qualitatively unchanged.

\section{E. Growth and Creative Destruction}


The remainder of this Section characterizes a balanced growth equilibrium with endogenous job destruction. It is easier to elaborate on this case by rewriting the FE locus as:

$$
\alpha=-2(r-\lambda g+\delta)+\frac{V / b}{r-\lambda g}\left[\frac{\beta}{1+\beta /(r-\lambda g+\delta)}\right]
$$

We can now examine the creative destruction effect. When the exogenous job separation rate $\left(\delta_{0}\right)$ increases, the $\mathrm{BC}$ locus does not shift whereas the FE locus rotates counter-clockwise as shown in Figure 7 (from FE to $\left.\mathrm{FE}^{\prime}\right)$. The corresponding changes in $\alpha$ and $\beta$ thus depend on the location of the $\mathrm{BC}$ locus. When $q_{0}$ is small (represented by $\mathrm{BC}^{a}$ ), the worker's contact rate rises whereas the machine's contact rate falls. The converse is true, however, when $q_{0}$ is large (as indicated by $\mathrm{BC}^{b}$ ). From (18), the direct job destruction effect of a larger $\delta_{0}$ is to discourage the adoption effort, but the indirect thick-matching effect through the endogenous contact rate $\alpha$ may offset the negative destruction effect when the matching market is primitive (for low values of $q_{0}$ ). As a consequence, it is possible that autonomous job destruction may be creative, resulting in a net increase in the technology adoption effort and hence a higher rate of economic growth.

Armed with the this analytic strategy, we can further investigate the long-run responses to an autonomous increase in the rate of exogenous technology arrival or average growth. Not surprisingly, there is a direct productivity effect that is creative by spurring adoption activity and fostering economic growth. However, there are two additional effects: (i) the endogenous destruction effect via a higher job separation rate discourages technology adoption and suppresses knowledge growth; (ii) the thick-matching effect via the worker's contact rate is generally ambiguous. In the case where matching is effective (high $q_{\mathrm{o}}$ ), we have a negative thick-matching effect, reinforcing the destruction effect. When matching is primitive (low $q_{0}$ ), the thick-matching effect adds to the creation effect. Therefore, whether a technological advancement is creative or destructive to existing jobs depends crucially on the degree of efficacy of job matching and the magnitudes of endogenous destruction versus productivity effects. 
We next consider the dynamic responses to exogenous shifts in technology arrival, focusing on the case with $\alpha=\alpha(N)$ and $s=s(J)$. Notice that endogeneity of job separation results in a modified Jacobian matrix $A^{\prime}=\left(a_{i j}{ }^{\prime}\right)$ where $\mathrm{a}_{11}{ }^{\prime}=a_{11}, \mathrm{a}_{12}{ }^{\prime}=\delta_{0} \lambda_{0}(1-N) \Delta_{\lambda}>0, \mathrm{a}_{21}{ }^{\prime}=a_{21}<0$ and $a_{22}{ }^{\prime}>a_{22}$. When $\alpha_{N}$ and $s_{J}$

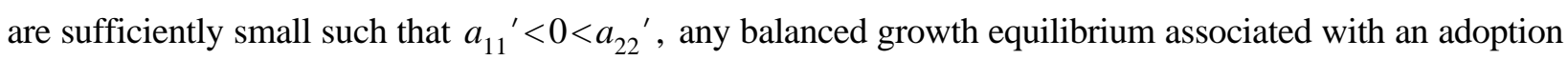
level satisfying the Correspondence Principle is saddle-path stable. More precisely, both $\dot{N}=0$ and $\dot{J}=0$ loci are upward-sloping in $(N, J)$ space where the former is steeper than the latter. While an exogenous increase in the technology arrival rate (higher $\lambda_{0}$ ) generates an instantaneous endogenous destruction effect via $\delta\left(\lambda_{0} s\right)$, there is an instantaneous jump in $J$ in conjunction with a gradual adjustment in $N$. As discussed above, the presence of market frictions implies that matching is not immediate and the response of technology adoption to $J$ exhibits a delay (or diffusion) of $L=1 /\left(\lambda_{0} s\right)$. The transitional movement in worker's contact rates must be also gradual given $\alpha=\alpha(N)$. As a consequence, any possible creation effects take time while the endogenous destruction effect is instantaneous. Thus, along the transition path, the economic growth rate must drop initially and eventually increases as the creation effects become the dominating forces. Furthermore, by examining the eigenvalues, it is easily seen that the considerations of endogenous job separation lead to a lower speed of convergence to the corresponding balanced growth path. In the absence of job destruction, Ortigueira and Santos (1997) and Eicher and Turnovsky (1999) find that the speed of convergence is higher under endogenous growth than exogenous growth. Our result suggests that the presence of endogenous job destruction dampens the positive effect of endogenous growth on the speed of convergence. Therefore, we can conclude:

Proposition 5: (Endogenous Growth and Creative Destruction) Assume the presence of endogenous job destruction. When matching efficacy is sufficiently low, a higher rate of exogenous job separation encourages technology adoption and enhances economic growth, while the thickness of matching enhances job creation unambiguously. When the balanced growth equilibrium is a saddle, an increase in the rate of 
exogenous technology arrival lower growth in the short run but spur the economy in the longer run.

Regardless of the effectiveness of matching, the presence of endogenous job destruction reduces the speed of convergence.

Under the constant-returns-to-scale matching framework, the scale effect is absence in the sense that the population size has no influence on long-run growth. This theoretical result is consistent with crosscountry empirical evidence, contrasting sharply with the R\&D-based canonical endogenous-growth models. Concerning the determinants of economic growth, there is always a direct productivity effect of technological advancements on the economy's rate of balanced growth, as in any endogenous growth models. However, previous studies diverge dramatically in additional factors that may affect economic growth. For example, Aghion and Howitt (1994) consider the endogenous destruction effect, Laing, Palivos and Wang (1995a) emphasize the thick matching effect, whereas Laing, Palivos and Wang (1995b) and Chen and Shimomura (1998) analyze the endogenous search intensity effect. In our paper, we allow for both endogenous destruction and thick-matching effects and illustrate that the working of the latter depends crucially on the efficacy of job matching. In particular, we show that the short-run destruction effect of a creative improvement in technology is likely to be more severe when job matching is more effective, which is new to the existing literature.

With regard to the growth and unemployment literature, Bean and Pissarides (1993) highlight the capitalization effect, while Aghion and Howitt (1994) study the interactions between effects from capitalization, direct destruction and indirect destruction (via entry). In our paper, we consider all different channels in a dynamic general-equilibrium search framework. In particular, Proposition 5 adds valuable insights to the state-of-art creative-destruction papers by Aghion and Howitt $(1992,1994)$. It suggests that creative destruction occurs not only through the replacement or job separation channel but possibly via a negative thick-matching effect, which is more significant in a developed economy with a greater degree of matching efficacy (such as in the U.S. or other OECD countries without a strong labor union). Since this 
latter effect is absent when the job-matching market is primitive, creative destruction is unlikely to play an important role in developing countries. Moreover, in contrast to the existing R\&D literature where the destruction effect is captured by the loss of monopoly rent (e.g., under either monopolistic competition or monopoly frameworks), our paper models explicitly the process of machine entry and exit in the job search market.

Finally, our results concerning autonomous changes in the job destruction rate are of empirical relevance as well. A study conducted by OECD (1987) states that Japan had the greatest rates of business closure (destruction) among OECD countries in the 1980s. Over the same period, however, the Japanese economy has experienced rapid growth with a high rate of start-up (creation) despite the second oil crisis occurred in 1979. It is well-documented that job matching in Japan has not been very effective due to the lack of labor mobility by social conventions and the presence of rigid government regulations. In terms of our language, this causes a higher likelihood for autonomous job separation to generate more technology adoption and thus fostering higher growth through job creation.

\section{F. Social Welfare Implications}

To the end, we would like to point out that the decentralized equilibrium based on the technology adoption effort specified as in Lemma 2 is in general socially suboptimal. This result need not rely on external economies or diseconomies, in contrast with previous studies. In addition to the external free-rider effect through $\lambda g$ (as in Romer, 1990, and many other endogenous growth studies), individuals in our model also fail to account for the thick-matching effect (via the worker's contact rate $\alpha$ ) and the direct and indirect destruction effect (via the job separation rate $\delta$ and endogenous entry). While the thick-matching effect results in under-investment in technology adoption that reinforces the free-rider effect, the endogenous destruction effect leads to an over-investment. This latter finding is new to the existing literature. ${ }^{10}$

${ }^{10}$ Although in Aghion and Howitt (1992) over-investment in R\&D is possible, it is due to an entirely different force, namely, the business-stealing effect due crucially to the monopoly setup. 
Summarizing,

Proposition 6: (Social Inefficiency of Equilibrium) With endogenous creative destruction, a balanced growth equilibrium is associated with under- or over-investment in technology adoption, except for a set of parameters of measure zero.

As one can see from equation (18), such social inefficiency is unlikely to be remedied by standard Pigovian taxes or subsidies. Although a Pigovian tax/subsidy may help to correct the over/under-investment in technology adoption, the corresponding changes in contact rates may make such incentive correction inadequate. Therefore, a socially optimal central planner program must consist of not only a Pigovian tax/subsidy but also an employment or industrial policy that can directly influence job creation and destruction (so as to correct the worker's contact rate $\alpha$ and the job separation rate $\delta$ ).

\section{Conclusions}

This paper develops a dynamic search-theoretic framework of technology adoption in which the interactions of endogenous matching and technology adoption give rises to the possibility of multiple equilibria (both global and local indeterminacy). It shows that labor market search and entry frictions can discourage adoption effort and lengthen technology diffusion. In the absence of endogenous job destruction, an increase in the rate of exogenous technology arrival or average growth spurs the worker's contact rate, encourages adoption activity and raises the wages, though its influence on the overall wage dispersion is ambiguous due to the conflicting effects on the long-term unemployed and the newly employed. In the presence of global indeterminacy, a small autonomous technological improvement may create a large longrun effect, lifting an economy from a low-growth trap to a high-growth equilibrium. Moreover, by incorporating endogenous job destruction, an increase in the rate of exogenous technology arrival may dampen growth in the short run but spur the economy in the longer run. Finally, the decentralized solution is 
socially inefficient except for a set of parameters of measure zero. In particular, individuals may under- or over-invest in technology adoption, as they fail to account for free-rider, thick-matching and endogenous destruction effects.

There are several extensions of this work that may be of significant interest. For brevity, however, we only discuss two. One extension is to calibrate our model to obtain a technology diffusion curve. One can then study how search frictions may influence the shape of diffusion curves. Another is to explore more on the finding that the dynamic effect of technology adoption on the severity of creative destruction depends on the extent of the job matching market. In particular, one may empirically test this theoretical proposition using data from countries of various development stages with different degrees of job matching efficacy. 


\section{References}

Aghion, Philip and Peter Howitt, 1992, A Model of Growth through Creative Destruction, Econometrica, 60, 232-351.

Aghion, Phillip and Peter Howitt, 1994, Growth and Unemployment, Review of Economic Studies 61, 477494.

Amsden, Alice H., 1991, Big Business and Urban Congestion in Taiwan: the Origins of Small Enterprises and Regionally Decentralized Industry, World Development, 19, 1121-1135.

Aw, Bee Yan, Xiaomin Chen and Mark J. Roberts, 1997, Firm-Level Evidence on Productivity Differentials, Turnover and Exports in Taiwanese Manufacturing, NBER working paper No. 6235.

Bean, Charles and Christopher Pissarides, 1993, Unemployment, Consumption and Growth, European Economic Review 37, 837-854.

Benhabib, Jess and Roberto Perli, 1994, Uniqueness and Indeterminacy: On the Dynamics of Endogenous Growth, Journal of Economic Theory, 63(3), 113-142.

Bond, Eric W., Ping Wang and Chong Yip, 1996, A General Two-Sector Model of Endogenous Growth with Human and Physical Capital: Balanced Growth and Transitional Dynamics, Journal of Economic Theory, 68(1), 149-173.

Boone, Jan, 1997, Technical Progress and Unemployment, Tilburg University CentER working paper No 97117.

Brock, William and David Gale, 1969, Optimal Growth under Factor Augmenting Process, Journal of Economic Theory, 1, 229-243.

Chen, Been-Lon, 1995, Self-Fulfilling Expectations, History, and the Big Push: A Search Equilibrium Model of Unemployment, Journal of Economics 61(3), 245-271.

Chen, Been-Lon and Koji Shimomura, 1998, Self-Fulfilling Expectations and Economic Growth: A Model of Technology Adoption and Industrialization, International Economic Review, 39(1), 151-170.

Diamond, Peter, 1982a, Aggregate Demand Management in Search Equilibrium, Journal of Political Economy 90, 881-894.

Diamond, Peter, 1982b, Wage Determination and Efficiency in Search Equilibrium, Review of Economic Studies, 49, 761-894.

Eicher, Theo S. and Stephen J. Turnovsky, 1999, Convergence in a Two Sector Non-Scale Growth Model, Journal of Economic Growth, 4, 413-429.

Fields, Gary S., 1685, Industrialization and Employment in Hong Kong, Korea, Singapore and Taiwan, in Walter Galenson ed., Foreign Trade and Investment Economic Growth in the Newly Industrializing Asian Countries, 333-378, Wisconsin: the University of Wisconsin Press. 
Grossman, Gene and Elhanan Helpman, 1991, Innovation and Growth in the Global Economy, Cambridge, MA: MIT Press.

Jones, Larry and Rodolfo Manuelli, 1990, A Convex Model of Equilibrium Growth: Theory and Policy Implications, Journal of Political Economy, 98(5), 1008-1038.

Laing, Derek, Theodore Palivos and Ping Wang, 1995a, Learning, Matching and Growth, Review of Economic studies 62(1), 115-129.

Laing, Derek, Theodore Palivos and Ping Wang, 1995b, R\&D in a Model of Search and Growth, American Economic Review, Papers and Proceedings, 85, 291-295.

Mansfield, Edwin, 1969, Industry Research and Development: Characteristics, Costs and Diffusion of Results, American Economic Review, LIX, 65-71.

Mortensen, Dale and Christopher Pissarides, 1994, Job Creation and Job Destruction in the Theory of Unemployment, Review of Economic Studies 61, 397-415.

Murphy, Kevin, Andrei Shelifer and Robert Vishiny, 1989, Industrialization and the Big Push, Journal of Political Economy, 97, 1003-1026.

OECD, 1987, Structural Adjustment and Economic Performance, Paris: OECD.

Ortigueira, Salvador and Manuel S. Santos, 1997, On the Speed of Convergence in Endogenous Growth Models, American Economic Review, 87(3), 383-400.

Parente, Stephen, 1995, A Model of Technology Adoption and Growth, Economic Theory, 6, 405-420.

Parente, Stephen and Edward Prescott, 1994, Barriers to Technology Adoption and Development, Journal of Political Economy, 102(2), 298-321.

Parente, Stephen and Edward Prescott, 1999, Monopoly Rights: A Barrier to Riches, American Economic Review 89(5), 1216-1233.

Pissarides, Christopher, 1985, Short-Run Equilibrium Dynamics of Unemployment, Vacancies and Real Wages, American Economic Review, 75(3), 676-690.

Romer, Paul, 1990, Endogenous Technical Change, Journal of Political Economy, 98(5), Part 2, 71-102.

Rustichini, Aldo and Schmitz, 1991, Research and Imitation in Long-Run Growth, Journal of Monetary Economics, 27(2), 271-292.

Stokey, Nancy, 1991, Human Capital, Product Quality and Growth, Quarterly Journal of Economics, 106, 587-616.

Xie, Danyang, 1994, Divergence in Economic Performance: Transitional Dynamics with Multiple Equilibria, Journal of Economic Theory, 63, 97-112. 
Figure 1: Steady State Search

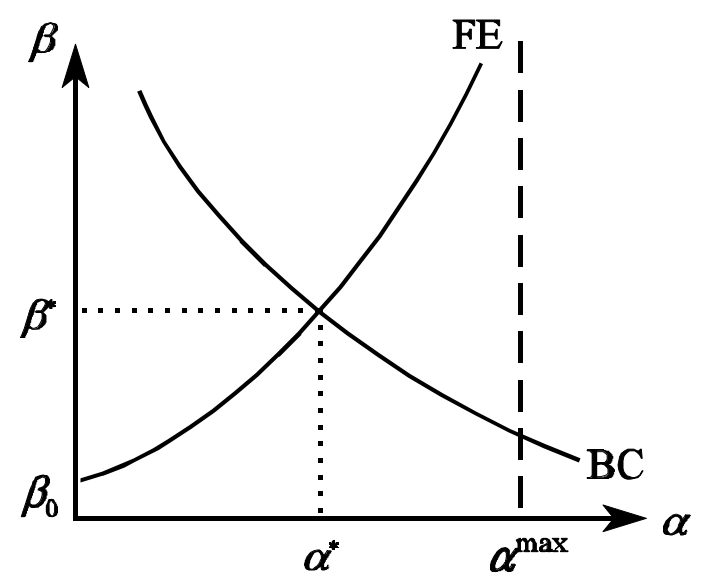

Figure 2a: Technology Adoption - Case I

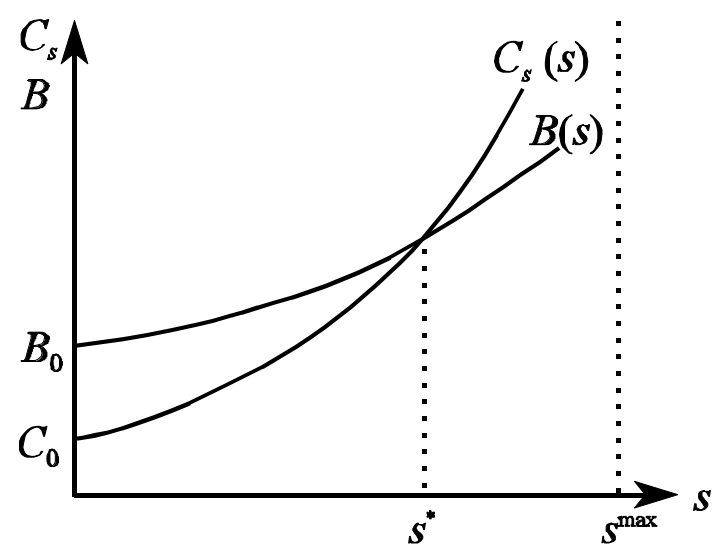

Figure 2b: Technology Adoption - Case II

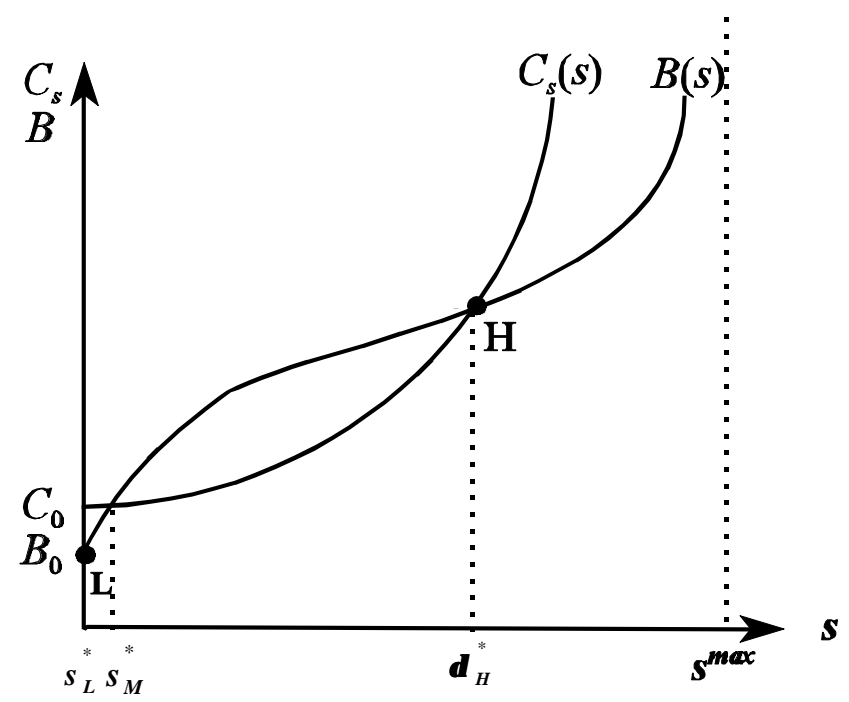


Figure 2c: Technology Adoption -Case III

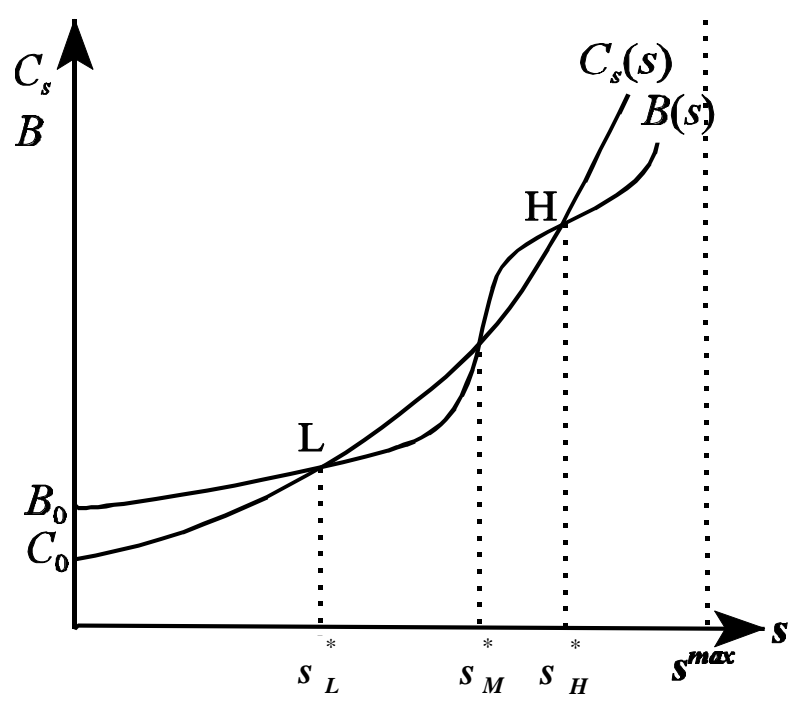

Figure 3: Technology Diffusion

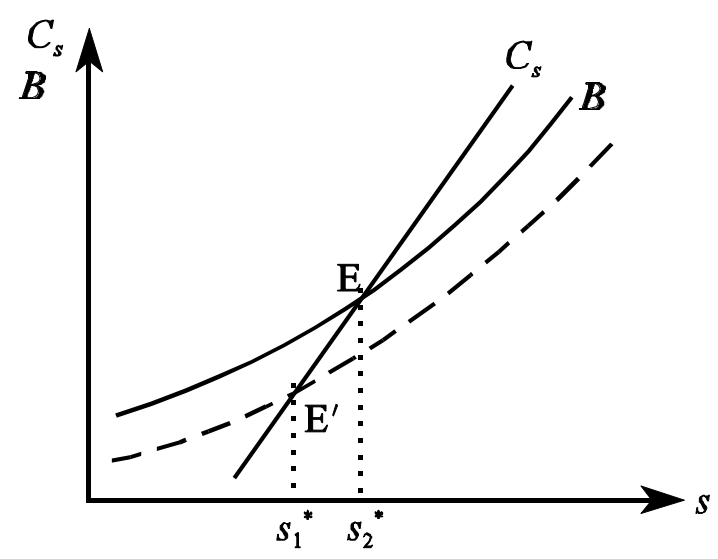

Figure 4: Comaparative Statics

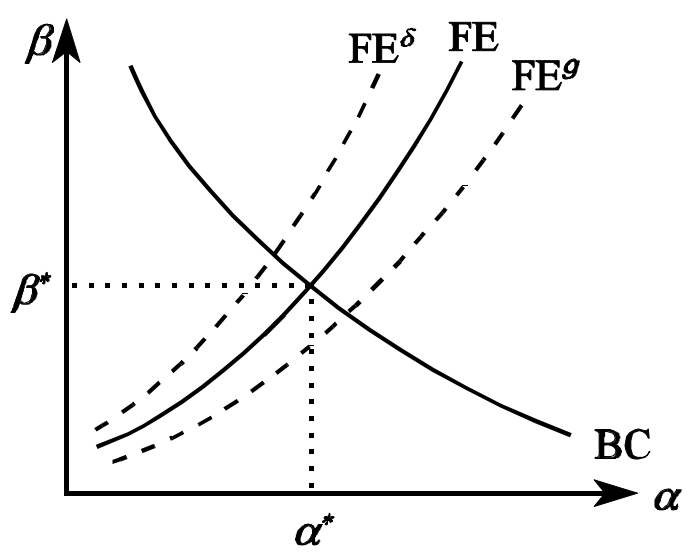


Figure 5: Wage Dispersion

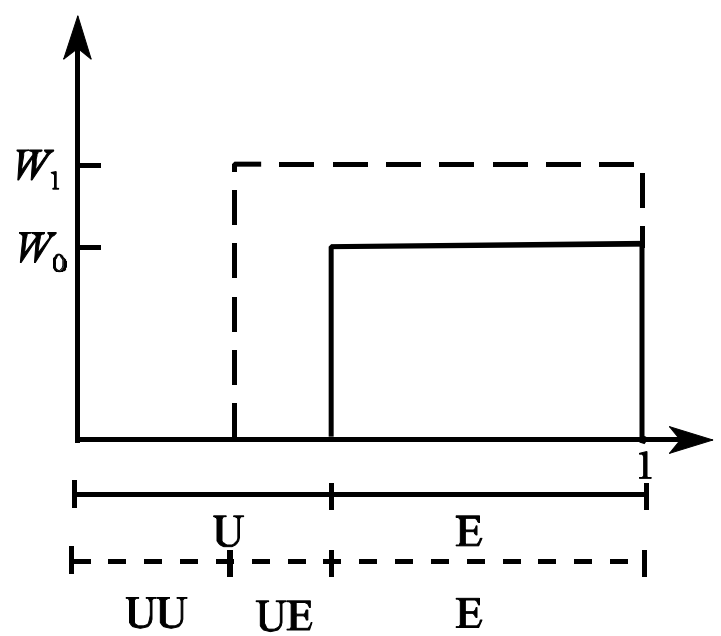

Figure 6 The Big Push

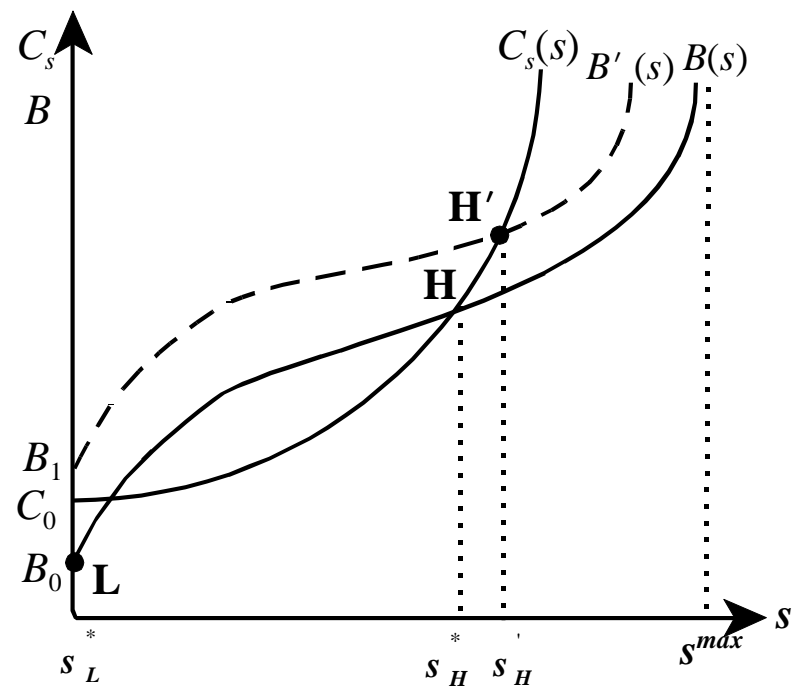

Figure 7: Creative Destruction

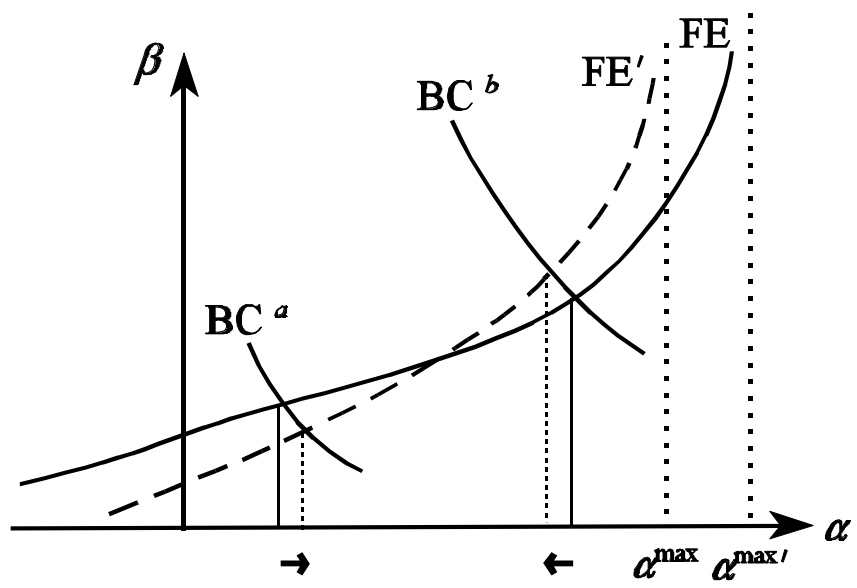


Table A: Summary of the Related Literature (Not Intended for Publication)

\begin{tabular}{|c|c|c|c|c|c|c|}
\hline & $\begin{array}{c}\text { (A) } \\
\text { growth, } \\
\text { unemployment } \\
\& \text { creative } \\
\text { destruction }\end{array}$ & $\begin{array}{c}\text { (B) } \\
\text { wage bargain }\end{array}$ & $\begin{array}{l}\text { (C) } \\
\text { endogenous growth }\end{array}$ & $\begin{array}{c}\text { (D) } \\
\text { technology } \\
\text { adoption } \\
\text { effort }\end{array}$ & $\begin{array}{c}\text { (E) } \\
\text { multiple } \\
\text { equilibria }\end{array}$ & $\begin{array}{c}(\mathrm{F}) \\
\text { social } \\
\text { inefficiency }\end{array}$ \\
\hline Boone (mimeo, 1997) & $x$ & $x$ & $\begin{array}{l}\text { R\&D, efficiency wage } \\
\text { model, } 6\end{array}$ & $x$ & $x$ & $(-)$ \\
\hline Aghion-Howitt (RES 94) & $1,2,3$ & $\begin{array}{l}\text { EG (direct effect) } \\
\text { JD (direct effect) }\end{array}$ & R\&D, search, $6,8,9$ & $x$ & MG, 11 & $x$ \\
\hline Laing-Palivos-Wang (RES 95) & 2,4 & $\mathrm{EG}(5)$ & $\mathrm{R} \& \mathrm{D}$, search, $6,7,9$ & $x$ & MG, 12 & $(-)$ \\
\hline Bean- Pissarides (RES 93) & 2. & EG (direct effect) & $\begin{array}{c}\text { Romer's (JPE 90) } \\
\text { AK model, Search, } 6\end{array}$ & $x$ & $x$ & $x$ \\
\hline Mortensen-Pissarides (RES 94) & $x$ & JD (direct effect) & $x$ & $x$ & $\times$ & $x$ \\
\hline Aghion-Howitt (EC 92) & $x$ & $x$ & R\&D, monopoly, 6 & $x$ & $\mathrm{LC}$ & $(-)$ or $(+), 14$ \\
\hline Grossman-Helpman (BK 91) & $x$ & $x$ & $\begin{array}{l}\text { R\&D, monopolistic } \\
\text { competition, } 6\end{array}$ & $x$ & $x$ & $(-)$ \\
\hline Diamond (RES 82) & $x$ & no EG, no JD & $x$ & $x$ & $x$ & $\times$ \\
\hline Pissarides (AER 85) & $\times$ & no EG, no JD & $x$ & $\times$ & $\times$ & $\times$ \\
\hline Parente-Prescott (JPE 94) & $x$ & $x$ & TA, Competitive, 6 & exogenous barrier & $x$ & $(-)$ \\
\hline Parente (ET95) & $x$ & $x$ & TA, Competitive, 6 & exogenous barrier & $x$ & $(-)$ \\
\hline Parente-Prescott (AER 1999) & $\times$ & $x$ & TA, Competitive, 6 & $\begin{array}{l}\text { monopoly } \\
\text { rent seeking }\end{array}$ & $x$ & $(-)$ \\
\hline Chen (JE 95), Diamond (JPE 82) & $x$ & $x$ & $x$ & $x$ & MS & $x$ \\
\hline Chen-Shimomura (IER 98) & $\times$ & $x$ & TA, search, 6,9,10 & search frictions & MG, 11 & $x$ \\
\hline Laing-Palivos-Wang (AER 95) & $x$ & $x$ & R\&D, search, $6,9,10$ & $\times$ & MG, 11 & $x$ \\
\hline $\begin{array}{l}\text { Chen-Mo-Wang (2000, } \\
\text { submitted to JEDC) }\end{array}$ & $1,2,3,4$ & $\begin{array}{c}\text { EG (5) } \\
\text { JD (thick matching) }\end{array}$ & TA, search, 6,7,8,9 & $\begin{array}{l}\text { search \& entry } \\
\text { frictions }\end{array}$ & MG, 13 & $\begin{array}{l}(-) 4,15 \\
(+) 1,3\end{array}$ \\
\hline
\end{tabular}

$\underline{\text { Notes: }}$ TA means "technology adoption"; $\times$ denotes "not applicable"; other notes are classified by column and summarized as follows:
(A)
1. direct creation destruction
(C)
(E)
2. capitalization / effective discounting
6. direct productivity
7. thick matching
MS = multiple steady states
3. indirect destruction via entry
8. endogenous destruction
$\mathrm{MG}=$ multiple growth paths
4. thick matching
9. no scale effect
$\mathrm{LC}=$ limit cycles
(B)
10. endogenous search
11. coordination failure via search intensity
$\mathrm{EG}=$ endogenous growth effect
$\mathrm{JD}=$ job destruction effect
intensity
12. matching and endogenous learning
13. matching and endogenous technology adoption
5. Liang, Palivos and Wang: via learning (F)
Chen-Mo-Wang: via technology adoption
(+) over-investment in equilibrium
(-) under-investment in equilibrium 